Dundee; Consultant Psychiatrist, Fife NHS Addiction Services.

\section{Brian Kidd,}

Senior Lecturer in Psychiatry, University of Dundee; Consultant Psychiatrist, Substance Misuse Service, NHS Tayside.

\section{Jonathan Bannister,}

Senior Lecturer in Anaesthetics, University of Dundee; Consultant Pain Specialist, Pain Clinic, Ninewells Hospital, Dundee.

\section{REFERENCES}

1. Torrance N, Smith BH, Bennett MI, Lee AJ. The epidemiology of chronic pain of predominantly neuropathic origin. Results from a general population survey. J Pain 2006; 7(4): 281-289.

2. Finnerup NB, Sindrup SH, Jensen TS. The evidence for pharmacological treatment of neuropathic pain. Pain 2010; 150(3): 573-581.

3. National Institute of Health and Clinical Excellence. Pharmacological management of neuropathic pain in non-specialist settings. NICE Clinical Guideline 96. London: NICE, 2010. http://guidance.nice.org.uk/CG96 laccessed on 4 Jul 2012)

4. BMA, Royal Pharmaceutical Society. British National Formulary, 62 (September 2011). London: BMJ Group and Pharmaceutical Press, 2010.

5. Scottish Drug and Crime Enforcement Agency, Forensic Science Unit. Report on the quality of diamorphine seized in Scotland, 2010-2011. Paisley: SCDEA, 2011. http://www.communityplanningaberdeen.org.uk/n msruntime/saveasdialog.asp? ||D=5715\&sID=1712 (accessed on 4 Jul 2012).

\section{The GP's role in improving the uptake of healthy start vitamins}

We were interested to read the editorial by Saxena et al." We agree that GPs are in an ideal position to support expectant mothers through their pregnancy and the postnatal period. An important aspect of any GP's role is of course health promotion and recently efforts have been made by local health authorities to encourage expectant mothers to consider vitamin D supplementation.

Symptomatic cases of vitamin D deficiency are on the rise in the UK and are especially common in young children from a South Asian, Middle Eastern, or African background. The Healthy Start programme entitles all pregnant women, new mothers, and young children from low income families to receive vouchers that can be exchanged for free vitamins. It is often believed that cultural, social, or language differences may explain the poor uptake of vitamin D supplementation in the above communities.

Between February-March 2012, we distributed a questionnaire to all mothers attending a health visitor clinic at a general practice in Glasgow to identify whether mothers with an adequate knowledge of English were aware of the Healthy Start programme and whether they administered vitamin supplements to their children. Out of 37 mothers approached, 34(92\%) questionnaires were returned. Most mothers ( $n=33,97 \%)$ were of white, Scottish ethnic origin with English as their native language. The median age of the infant attending the clinic was 4 months (range 1-4). During the pregnancy, none of the mothers took Healthy Start vitamins, despite being eligible in terms of family income. Ten mothers (29\%) paid for overthe-counter vitamins for pregnancy. Only three mothers (8\%) could recall receiving written information about vitamin supplementation in infants and eight mothers (24\%) recalled receiving verbal information. Of the 14 infants who were eligible for Healthy Start vitamins, four (29\%) were taking vitamin supplements and only one of these was taking Healthy Start vitamins.

This audit highlights that there is poor uptake of the Healthy Start programme, even in groups whose native language is English. It is clear that new mothers are not sufficiently well informed of the availability of vitamin D supplementation during pregnancy and infancy. By improving awareness of vitamin supplementation, GPs could make a clear difference to the health of the mother and the young child.

\section{Angela Lucas-Herald,}

FY2 in Paediatrics, Department of Child Health, Royal Hospital for Sick Children,

Dalnair Street, Glasgow.

E-mail: angelalhadoctors.org.uk

\section{Katherine Grosset,}

GP, Cairns Practice, Old Shettleston Road, Glasgow.

\section{Morag Robertson,}

Health Visitor, Cairns Practice, Old Shettleston Road, Glasgow.
Syed Faisal Ahmed,

Professor, Paediatric Endocrinology Consultant, Department of Child Health, Royal Hospital for Sick Children, Dalnair Street, Glasgow.

\section{REFERENCE}

1. Saxena S, Francis N, Sharland M. Primary care of children: the role of GPs. Br J Gen Pract 2012. DOI: 10.3399/bjgp12X652166.

\section{DOI: 10.3399/bjgp12X653525}

\section{Whose compass for morality?}

The world is full of contradiction, and so it is among the pages of the BJGP! Take the article from Andrew Moscrop on clinical leadership ${ }^{1}$ and set it alongside the paper from Andrew Lee et al on commissioning. Both impact directly on the need for a moral compass in clinical commissioning. Lee et al have no doubts about their morality. For them (as with NICE) utilitarianism is the moral philosophy to apply in clinical commissioning: "the greatest benefit for the greatest number', but without specifying what constitutes 'benefit'. At least Bentham (founder of utilitarianism) was more specific with 'happiness' as the magnetic North of the moral compass. If only life were so simple! In what reads like special pleading on behalf of public health specialists Lee et al argue both for the pre-eminence of population over the individual and, curiously, the balancing of competing voices. In contrast, Moscrop embraces complexity in his impassioned plea for a 'moral compass' in leadership. He makes a strong case for the central role of values but advocates uncovering and perhaps challenging wellestablished assumptions, behaviours, values, and beliefs' (perhaps including utilitarianism?). Crucially, he proposes a 'shared morality' though he leaves this idea hanging in the air.

I suggest Moscrop's argument could be developed using the notion of distributed leadership originating from education. ${ }^{3}$ Here both the determination of what is good and the bearing of responsibility are shared among a wide community of stakeholders, though accountability usually remains with a designated leader. The moral compass consists in a few high-order shared values pertaining to what it takes for humans and the environment to flourish. This is best 